\title{
Экспрессия генов адренорецепторов в сосудистой стенке у гипертензивных крыс линии НИСАГ (ISIAH)
}

\author{
М.А. Рязанова ${ }^{1}$, А.Л. Маркель ${ }^{1,2}$
}

Аннотация: Артериальная гипертония - широко распространенное заболевание, снижающее качество жизни и приводящее к фатальным сердечно-сосудистым осложнениям. Симпатоадреналовая система участвует в регуляции артериального давления и патогенезе артериальной гипертонии. Также симпатоадреналовая система является одной из ведущих причин появления реакции на стрессовые события. На сегодняшний день известно, что стресс в совокупности с наследственной предрасположенностью является одним из важных факторов, способствующих развитию артериальной гипертонии в человеческой популяции. В Институте цитологии и генетики СО РАН путем селекции на повышение артериального давления в условиях мягкого эмоционального стресса получены крысы линии НИCAГ (ISIAH), которые характеризуются рядом морфологических и физиологических признаков, свойственных больным артериальной гипертонией. Исследования указывают на повышенную функцию симпатоадреналовой системы у крыс гипертензивной линии НИСАГ. Повышение артериального давления в ответ на стрессовую стимуляцию может также зависеть от генетически обусловленного изменения профиля экспрессии генов адренорецепторов в артериальной стенке. Цель работы - исследовать экспрессию генов альфа1А-, альфа1В-, альфа2А-, бета1- и бета2-адренорецепторов в сосудистой стенке артерии у крыс НИСАГ со стресс-чувствительной артериальной гипертонией. Методом ПЦР в реальном времени показано снижение уровня экспрессии мРНК генов Adra1A и Adra1B адренорецепторов, опосредующих вазоконстрикцию в хвостовой артерии у крыс НИСАГ, что может указывать на компенсаторные изменения экспрессии генов адренорецепторов при артериальной гипертензии. Показано отсутствие экспрессии мРНК гена бета1-адренорецепторов в артериальной стенке у крыс НИСАГ, что свидетельствует о преобладающей роли бета2-адренорецепторов в этом сосуде.

Ключевые слова: альфа1А-адренорецепторы; альфа1В-адренорецепторы; альфа2А-адренорецепторы; бета1-адренорецепторы; бета2-адренорецепторы; ПЦР в реальном времени; артериальные сосуды; артериальная гипертония; крысы НИСАГ.

Благодарности: Работа выполнена при поддержке бюджетного проекта № 0259-2021-0016.

Для цитирования: Рязанова М.А., Маркель А.Л. Экспрессия генов адренорецепторов в сосудистой стенке у гипертензивных крыс линии НИСАГ (ISIAH). Письма в Вавиловский журнал генетики и селекции. 2021;7(1):12-16. DOI 10.18699/LettersVJ2021-7-02

Original article

\section{Expression of adrenergic receptor genes in the vascular wall of hypertensive ISIAH rats}

\author{
M.A. Ryazanova ${ }^{1}$, A.L. Markel ${ }^{1,2}$
}

\begin{abstract}
Arterial hypertension is a common disease, which reduces the quality of life and leads to fatal cardiovascular complications. The sympathetic adrenal system is involved in the regulation of blood pressure and in the pathogenesis of arterial hypertension. To date, it is known that stress, together with a hereditary predisposition, is one of the important factors contributing to the development of arterial hypertension in the human population. Using selection for an increase in blood pressure under conditions of mild emotional stress, ISIAH rats that are characterized by a number of morphological and physiological traits typical for patients with essential hypertension were obtained at the Institute of Cytology and Genetics of Siberian Branch of the Russian Academy of Sciences (Novosibirsk, Russia). The studies point to increased sympathetic adrenal system function in the hypertensive ISIAH line. However, an increase in blood pressure in response to stress stimulation is possible may depend on a genetically determined change in the expression profile of adrenergic receptor genes in the arterial wall. The aim of the work was to study the expression of alpha1A-, alpha1B-, alpha2A-, beta1-, beta2-adrenergic receptor genes in the vascular artery wall of ISIAH rats with stress-sensitive arterial hypertension. Decreased mRNA levels of Adra1A and Adra1B adrenoreceptor genes mediating vasoconstriction in the tail artery in ISIAH rats have been found, which may indicate compensatory changes under conditions of arterial hypertension. In addition, the absence of mRNA expression of the beta1-adrenergic receptor gene in the arterial wall of the studied rat strain was shown, which indicates on predominant role the beta2-adrenergic receptors in this vessel.
\end{abstract}

Федеральный исследовательский центр Институт цитологии и генетики Сибирского отделения Российской академии наук, Новосибирск, Россия

${ }^{2}$ Новосибирский национальный исследовательский государственный университет, Новосибирск, Россия

' Institute of Cytology and Genetics of Siberian Branch of the Russian Academy of Sciences, Novosibirsk, Russia

${ }^{2}$ Novosibirsk State University, Novosibirsk, Russia

هocean-2006@yandex.ru

(C) Рязанова М.А., Маркель А.Л., 2021 
Key words: alpha1A-adrenergic receptors; alpha1B-adrenergic receptors; alpha2A-adrenergic receptors; beta1-adrenergic receptors; beta2-adrenergic receptors; real-time PCR; arterial vessels; arterial hypertension; ISIAH rats.

For citation: Ryazanova M.A., Markel A.L. Expression of adrenergic receptor genes in the vascular wall of hypertensive ISIAH rats. Pisma v Vavilovskii Zhurnal Genetiki i Selektsii = Letters to Vavilov Journal of Genetics and Breeding. 2021;7(1):12-16. DOI 10.18699/LettersVJ2021-7-02 (in Russian)

\section{Введение}

Артериальная гипертония - широко распространенное заболевание, снижающее качество жизни и приводящее к фатальным сердечно-сосудистым осложнениям. Симпатоадреналовая система (CAC) участвует в регуляции артериального давления (АД) и патогенезе артериальной гипертонии. Также САС является одной из ведущих причин реакции на стрессовые события. На сегодняшний день известно, что стресс в совокупности с наследственной предрасположенностью способствует развитию гипертонии в человеческой популяции. В Институте цитологии и генетики СО РАН путем селекции на повышение АД в условиях мягкого эмоционального стресса (Markel, 1992) получены крысы линии НИСАГ (ISIAH), которые характеризуются рядом морфологических и физиологических признаков, свойственных пациентам с гипертонической болезнью, в том числе гипертрофией стенок левого желудочка и мелких артериальных сосудов (Маркель и др., 1985; Markel, 1992; Максимов и др., 1999).

В действительности сердце и сосуды являются тем конечным звеном, на которое направлена стимуляция со стороны САС и ренин-ангиотензиновой системы, приводящая к повышению АД. Ранее показано, что гипертензивное состояние у крыс НИСАГ связано не с гиперфункцией ренин-ангиотензиновой системы (Amstislavsky et al., 2005) (гипертонию у крыс НИСАГ можно охарактеризовать как низкорениновую), а скорее с повышением тонуса САС (Markel et al., 1999; Markel et al., 2007; Рязанова, 2012). Это ожидаемо, так как селекция линии крыс НИСАГ велась на повышение уровня АД в условиях мягкого эмоционального стресса, связанного с активацией центральной нервной системы и ее симпатического отдела. Однако повышение АД в ответ на стрессовую стимуляцию возможно не только по причине усиленного ответа со стороны САС, но и вследствие увеличения реактивности сердечно-сосудистой системы на симпатический разряд. В нашем случае можно предположить, что в результате селекции на повышенный уровень АД в условиях стресса могла сформироваться соответствующая генетическая база, обеспечивающая повышенный ответ мелких артериальных сосудов, от которых зависит общее сопротивление кровотоку и уровень АД, на симпатическую стимуляцию. Такое повышение реактивности сосудов может быть следствием генетически обусловленного изменения профиля экспрессии генов адренорецепторов в артериальной стенке.

Задачей работы было изучение транскрипционной активности генов адренорецепторов в стенке артерий мышечного типа у крыс линии НИСАГ в сравнении с нормотензивными крысами Вистар (WAG). В качестве мишени избрана вентральная артерия хвоста крысы. Исследована экспрессия генов следующих адренорецепторов: альфа1А, альфа1В, альфа2А, бета1 и бета2.

\section{Материалы и методы}

Исследование проведено на трехмесячных крысахсамцах двух инбредных линий: НИСАГ (ISIAH), $\mathrm{n}=6$, и WAG (Wistar Albino Glaxo), $\mathrm{n}=5$. Крыс содержали в стандартных условиях вивария Института цитологии и генетики СО РАН со свободным доступом к воде и сбалансированному корму. Исследование выполнено в соответствии с международными правилами по работе с экспериментальными животными (Этический кодекс от 1985 г.). В возрасте 3 мес. крыс взвешивали, измеряли АД непрямым методом (tail-cuff method) на аппарате CODA-HT8 (Kent Scientific, США). Через 5 дней крыс декапитировали, хвостовую артерию быстро выделяли и помещали в жидкий азот, а затем хранили при $-70{ }^{\circ} \mathrm{C}$ для дальнейшего выделения РНК.

Выделение суммарной РНК из хвостовой артерии проводили с использованием TRI Reagent (RNA/DNA/Protein isolation agent, Molecular Research Center, США) согласно рекомендациям производителя, с некоторыми модификациями.

Примеси геномной ДНК удаляли с помощью ДНКазы (Promega, США) согласно рекомендациям производителя. Концентрацию РНК измеряли в водном растворе с помощью спектрофотометра Nanodrop 2000 (Thermo Scientific, США) по поглощению на 260 нм. Качественными считали образцы PHK, для которых D260/D280 $\approx 2.0$. Для получения кДНК смешивали 1 мкг РНК и 0.25 нмоль случайных (random N9) праймеров-наномеров (ПАО «Биосинтез», Россия). Конечный раствор смеси реакции обратной транскрипции объемом 50 мкл содержал: 1 мкг РНК и 0.25 нмоль случайных праймеров-наномеров (ПАО «Биосинтез», Россия), 5 мкл буфера F2, 5 мкл 4 мM dNTP, 25 мкл 40\% трегалозы, 1 мкл BSA (10 мг/мл) и 5 мкл 40 ед. акт. обратной транскриптазы MoMLV (реактивы производства AO «Вектор-Бест», Россия). Синтез кДНК проводили при $37^{\circ} \mathrm{C}-1$ ч, $42^{\circ} \mathrm{C}-50$ мин, $50{ }^{\circ} \mathrm{C}-10$ мин. Фермент инактивировали при $75^{\circ} \mathrm{C}$ в течение 5 мин.

Для проверки отсутствия геномной ДНК в полученных растворах проводили ПЦР с раствором РНК и праймерами на ген Adra2A (Рязанова и др., 2017). Оценку качества обратной транскрипции для каждого образца кДНК проверяли постановкой ПЦР в реальном времени с праймерами на ген $R_{\text {зо }}$ (Рязанова и др., 2017).

ПЦР в реальном времени проходила в следующем температурном режиме: предварительный прогрев при $94{ }^{\circ} \mathrm{C}-$ 2 мин, затем 38-45 циклов: денатурация при $94^{\circ} \mathrm{C}-15$ с, отжиг - 20 с, элонгация при $72{ }^{\circ} \mathrm{C}-20$ с, сбор данных по флуоресценции - 10 с (таблица). После окончания ПЦР снимали кривые плавления для контроля специфичности реакции. Полуколичественную оценкуэкспрессии мРНК исследуемых генов осуществляли с помощью ПЦР в реальном времени 
Праймеры, используемые для ПЦР в реальном времени Gene-specific primers used for RT-PCR

\begin{tabular}{|c|c|c|c|c|}
\hline \multirow{2}{*}{ Ген / Gene } & \multirow{2}{*}{ Праймеры / Primer sequence } & \multicolumn{2}{|r|}{$\mathrm{T},{ }^{\circ} \mathrm{C}$} & \multirow{2}{*}{$\begin{array}{l}\text { Длина продукта, } \\
\text { п.н. / Amplificate } \\
\text { fragment, bp. }\end{array}$} \\
\hline & & Отжиг / Annealing & Регистрация / Detection & \\
\hline $\mathrm{RpI}_{30}$ & $\begin{array}{l}\mathrm{F}: 5^{\prime}-\text { ATGGTGGCTGCAAAGAAGAC-3' } \\
\mathrm{R}: \text { 5'- CAAAGCTGGACAGTTGTTGG -3' }^{\prime}\end{array}$ & $61-64$ & 84 & 165 \\
\hline Adra1A & $\begin{array}{l}\text { F: 5' - TGCCATCTTTGAGATCCTG-3' } \\
\text { R: 5'- GGTAGCTCACACCAATGTA -3' }\end{array}$ & 64 & 87 & 143 \\
\hline Adra1B & $\begin{array}{l}\text { F: 5' - CCAAAACCTTGGGCATTGTA -3' } \\
\text { R: 5'- TAGATGATGGGATTGAGGCA -3' }\end{array}$ & 64 & 87 & 166 \\
\hline Adra2A & $\begin{array}{l}\text { F: 5'-TATGGGCTACTGGTACTTT-3' } \\
\text { R: 5'-CCCACACAGTGACAATGAT-3' }\end{array}$ & 63 & 90 & 191 \\
\hline Adrb1 & $\begin{array}{l}\text { F: 5'-CAAGACACTGGGCATCAT-3' } \\
\text { R: 5'-CCAGTTGAAGAAGACGAAGA-3' }\end{array}$ & 64 & 87 & 124 \\
\hline Adrb2 & $\begin{array}{l}\text { F: 5'-ACTCTGCCTTCAATCCTCTTA-3' } \\
\text { F: 5'-TTCATTTTCTTTCTCCTGCCC-3' }\end{array}$ & 62 & 85 & 188 \\
\hline
\end{tabular}

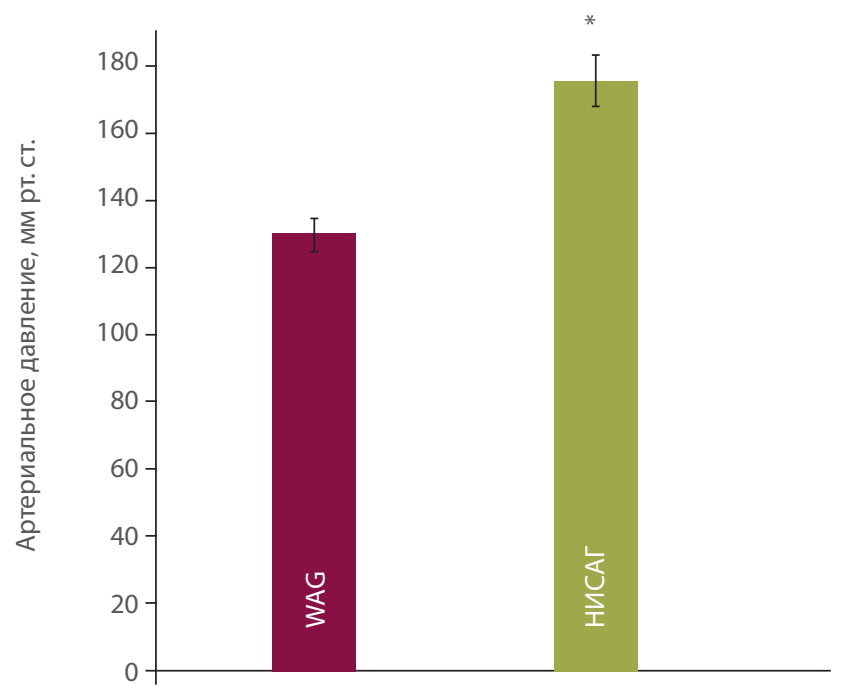

Рис. 1. Величина артериального давления у крыс линий WAG и НИСАГ при стрессе (измерение при помещении животного в сетчатую трубку)

* $p<0.05$ по сравнению с крысами WAG, критерий Манна - Уитни

Fig. 1. The value of blood pressure in WAG rats and ISIAH rats under stress (measurement in a mesh tube)

* significantly different from WAG, $p<0.05$, Mann - Whitney U-test

относительно количества мРНК гена домашнего хозяйства $\mathrm{Rpl}_{30 .}$ Из полученных образцов кДНК для каждой структуры делали усредненный раствор кДНК, который использовали для построения калибровочных кривых, по которым определяли относительный уровень кДНК для целевых генов и гена сравнения в образцах. Праймеры, используемые для определения экспрессии генов (см. таблицу), были подобраны с использованием онлайн-олигоанализатора (https:// www.eu.idtdna.com) и проверены в базе данных Blast (Basic Local Alignment Search Tool) на специфичность.

Статистическую обработку данных проводили с исполь- зованием пакета программ Statistica 10.0. Анализ экспрессии генов выполняли с помощью методов непараметрической статистики с использованием критерия Манна - Уитни.

\section{Результаты}

Масса тела трехмесячных крыс НИСАГ составила $295.8 \pm$ \pm 10.5 г, WAG - $282.3 \pm 7.6$ г. Уровень АД у крыс НИСАГ был достоверно выше, чем у крыс WAG (рис. 1). Исследование экспрессии генов адренорецепторов в стенке хвостовой артерии у крыс гипертензивной линии НИСАГ показало статистически значимое снижение количества мРНК генов альфа1А- и альфа1В-адренорецепторов (рис. 2) по сравнению с крысами WAG. Экспрессии генов альфа2A- и бета2-адренорецепторов достоверно не различались у нормо- и гипертензивных крыс, а экспрессия бета1-адренорецептора у обеих исследованных линий крыс была очень низкой (на грани чувствительности метода) (см. рис. 2).

\section{Обсуждение}

Симпатоадреналовая система опосредует реакцию на стрессовые воздействия путем взаимодействия норадреналина и адреналина со специфическими мембранными G-белок-связанными адренергическими рецепторами, вызывая соответствующие физиологические ответы организма. Регуляция просвета кровеносных сосудов является важным параметром, определяющим общее сопротивление кровяного русла кровотоку и, как следствие, уровень АД. Именно поэтому активацию САС рассматривают в качестве одного из основных факторов патогенеза эссенциальной артериальной гипертонии. Предполагают, что периодическая избыточная активация САС, в том числе в условиях хронического стресса, напрямую участвует в развитии гипертонической болезни (Fink, 2009; Hering et al., 2015). Повышенное АД впоследствии становится фактором развития изменений структуры и функции сосудов различного калибра, которые в свою очередь рассматриваются как органы-мишени при гипертонии. Эти изменения, вызванные повышенным артериальным давлением, способствуют формированию патологии в различных органах, главным обра- 


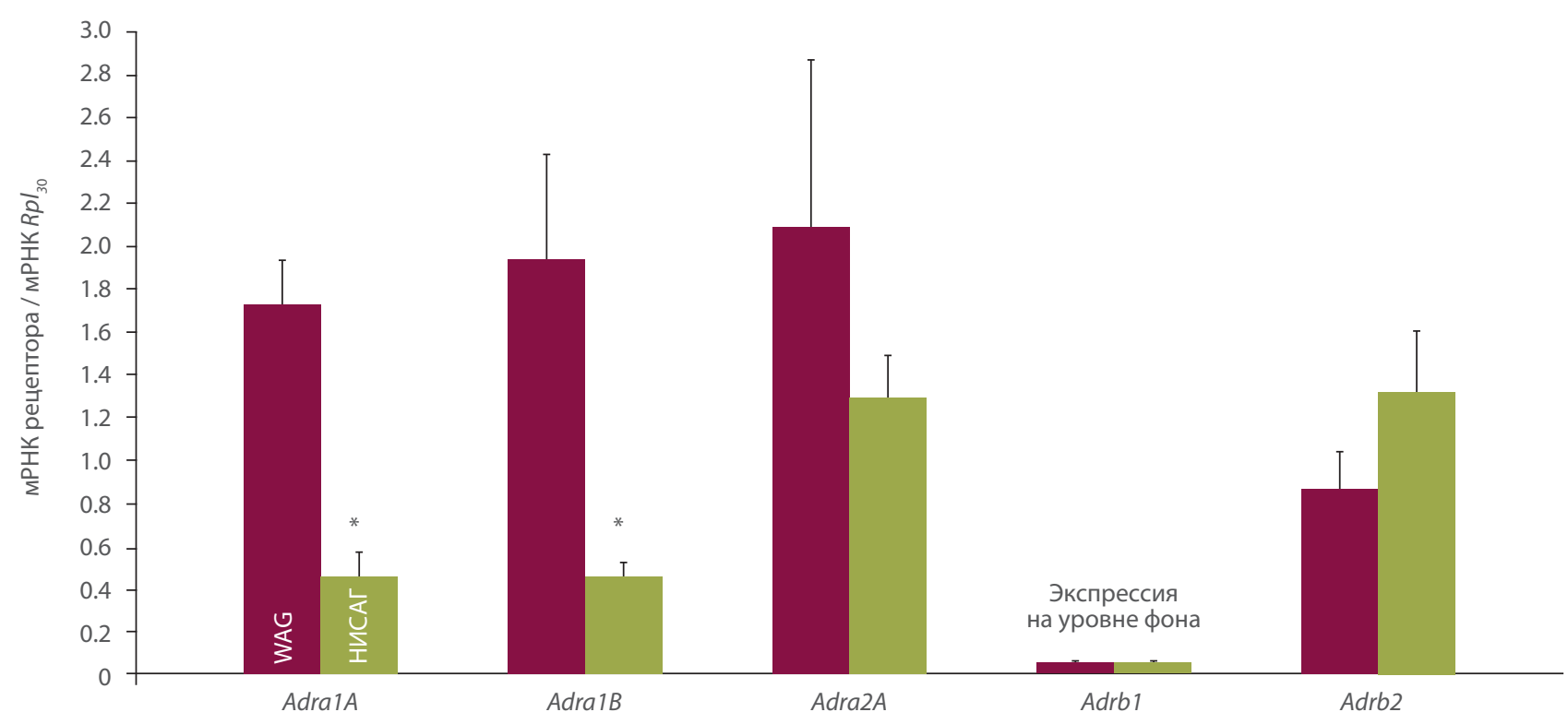

Рис. 2. Содержание мРНК генов адренорецепторов в хвостовой артерии у крыс линий WAG и НИСАГ * $p<0.05$ по сравнению с крысами WAG, критерий Манна - Уитни

Fig. 2. MRNA content of adrenergic receptor genes in the tail artery of WAG and ISIAH rats * significantly different from WAG rats, $p<0.05$, Mann - Whitney U-test

зом почках, поддерживая высокое АД (Grassi et al., 2009; Назарова О.А., Назарова А.В., 2012). В регуляции сосудистого тонуса со стороны САС принимают участие альфа1-, альфа2и бета-адренорецепторы, локализованные в стенке сосудов (Guimaraes, Moura, 2001). В данной работе исследованы альфа1А-, альфа1В-адренорецепторы как наиболее распространенные в сосудах и реализующие вазоконстрикторные эффекты норадреналина (Piascik et al., 1990; Jähnichen et al., 2004; Docherty, 2010), а также альфа2А-адренорецепторы как основные регуляторы выхода норадреналина в синаптическую щель посредством отрицательной обратной связи (Altman et al., 1999; Hein et al., 1999; Bucheler et al., 2002). Kрoме того, исследованы бета1- и бета2-адренорецепторы, стимуляция которых вызывает главным образом релаксацию гладкомышечных клеток сосудов. При этом следует учесть, что вовлечение каждого подтипа бета-адренорецепторов в этот процесс зависит от локализации в сосуде и вида животного (O'Donnell, Wanstall, 1984; Guimaraes et al., 1993; Shen et al., 1994; Begonha et al., 1995).

Наличие стойкого гипертензивного статуса у крыс линии НИСАГ предполагало повышение экспрессии генов адренорецепторов альфа1А и альфа1В, посредством которых и реализуются вазоконстрикторные влияния САС. Однако вопреки ожиданиям в нашем случае экспрессия генов этих адренорецепторов оказалась значительно ниже (см. рис. 2). При этом следует учитывать, что продукция норадреналина и адреналина - факторов, стимулирующих адренорецепторы, - у крыс НИСАГ значительно повышена (Markel et al., 2007). То есть наблюдается типичная картина реципрокного взаимоотношения концентраций лиганда и рецептора, которая описана для разнообразных регуляторных си- стем (Wilkinson et al., 1994; Ranheim et al., 1995; Morel et al., 2000; Red-Horse et al., 2001). Таким образом, можно сделать следующий главный вывод: рост уровня симпатической стимуляции сосудистой системы у крыс НИСАГ имеет центральное происхождение за счет повышения тонуса мозговых центров регуляции симпатической активности. Подтверждением этому служат недавно полученные данные об увеличении концентрации норадреналина в гипоталамусе крыс НИСАГ (неопубликованные результаты). В литературе также не представлено данных об усилении альфа-адренергического рецепторного звена в сосудистой системе у крыс с экспериментальной артериальной гипертонией (Michel et al., 1990; Luo et al., 2003). Результаты у больных артериальной гипертонией весьма противоречивы и не дают однозначной оценки, что свидетельствует о значительной гетерогенности патогенетических механизмов гипертонической болезни у людей.

\section{Заключение}

Впервые получены данные об особенностях адренорецепторного звена сосудистой стенки у крыс НИСАГ с наследственной индуцированной стрессом артериальной гипертонией. Показан низкий уровень экспрессии мРНК генов альфа1А- и альфа1В-адренорецепторов, опосредующих вазоконстрикцию, что может указывать на компенсаторные изменения в условиях артериальной гипертензии. Кроме того, продемонстрировано отсутствие экспрессии мРНК гена бета1-адренорецептора в вентральной хвостовой артерии у исследованных линий крыс, что свидетельствует о преобладающей роли бета2-адренорецепторов в этом сосуде. 


\section{Список литературы / References}

Максимов В.Ф., Коростышевская И.М., Маркель А.Л., Филюшина Е.Е., Шмерлинг М.Д., Якобсон Г.С. Метаболическое повреждение миокарда у нормотензивных и гипертензивных крыс (морфометри ческий анализ). Морфология. 1999;115(1):19-23.

[Maksimov V.F., Korostyshevskaya I.M., Markel A.L., Filyushina E.E., Schmerling M.D., Jacobson G.S. Metabolic myocardial injury in normotensive and hypertensive rats (morphometric analysis). Morfologia = Morphology. 1999;115(1):19-23. (in Russian)]

Маркель А.Л., Ерисковская Н.К., Еремеев С.И., Семенова Л.А., Целлариус Ю.Г. Адреналиновые повреждения миокарда у крыс с наследственно обусловленной артериальной гипертензией. Бюлл. экспер. биол. и мед. 1985;99(3):356-358.

[Markel A.L., Eriskovskaya N.K., Eremeev S.I., Semenova L.A., Cellarius Yu.G. Adrenaline myocardial injury in rats with hereditary arterial hypertension. Byulleten Eksperimentalnoy Biologii i Meditsiny = Bulletin of Experimental Biology and Medicine. 1985;99(3):356-358. (in Russian)]

Назарова О.А., Назарова А.В. Поражение сосудов при артериальной гипертензии. Вестник Ивановской медицинской академии. 2012;17(2):60-66

[Nazarova O.A., Nazarova A.V. Vascular lesion in arterial hypertension. Vestnik Ivanovskoy Medicinskoy Academii = Bulletin of the Ivanovo Medical Academy. 2012;17(2):60-66. (in Russian)]

Рязанова М.А., Прокудина О.И., Плеканчук В.С., Алехина Т.А. Экспрессия генов системы катехоламинов в среднем мозге и реакция престимульного торможения у крыс с генетической кататонией. Вавиловский журнал генетики и селекции. 2017;21(7):798-803. DOI 10.18699/VJ17.296.

[Ryazanova M.A., Prokudina O.I., Plekanchuk V.S., Alekhina T.A. Expression of catecholaminergic genes in the midbrain and prepulse inhibition in rats with a genetic catatonia. Vavilovskii Zhurnal Genetik i Selektsii = Vavilov Journal of Genetics and Breeding. 2017;21(7):798803. DOI 10.18699/VJ17.296. (in Russian)]

Рязанова М.А. Экспрессия генов альфа1А- и альфа2А-адренорецепторов в миокарде и ткани почки у гипертензивных крыс линии НИСАГ (ISIAH). Бюлл. СО РАMН. 2012;32(1):43-47.

[Ryazanova M.A. Expression of the Alpha1A and Alpha2A adrenergic receptor genes in myocardial and kidney tissues of hypertensive ISIAH rats. Bull. SO RAMN = Bull. SB RAMS. 2012;32(1):43-47. (in Russian)]

Altman J.D., Trendelenburg A.U., Macmillan L., Bernstein D., Limbird L., Starke K., Kobilka B.K., Hein L. Abnormal regulation of the sympathetic nervous system in a2A-adrenergic receptor knockout mice. Mol. Pharmacol. 1999;56:154-161. DOI 10.1124/mol.56.1.154.

Amstislavsky S., Welker P., Fruhauf J.H., Maslova L., Ivanova L., Jensen B. Markel A.L., Bachmann S. Renal and endocrine changes in rats with inherited stress-induced arterial hypertension (ISIAH). Histochem Cell Biol. 2005;8:1-9. DOI 10.1007/s00418-005-0118-5.

Begonha R., Moura D., Guimaraes S. Vascular b-adrenoceptor-mediated relaxation and the tone of the tissue in canine arteries. J. Pharm Pharmacol. 1995;47:510-513. DOI 10.1111/j.2042-7158.

Bucheler M.M., Hadamek K., Hein L. Two alpha(2)-adrenergic receptor subtypes, alpha(2A) and alpha(2C), inhibit transmitter release in the brain of gene-targeted mice. Neuroscience. 2002;109:819-826. DOI 10.1016/S0306-4522(01)00531-0.

Docherty J.R. Subtypes of functional alpha1-adrenoceptor. Cell Mol. Life Sci. 2010;67(3):405-417. DOI 10.1007/s00018-009-0174-4.

Fink G.D. Sympathetic activity, vascular capacitance, and long-term regulation of arterial pressure. Hypertension. 2009;53:307-312. DOI 10.1161/HYPERTENSIONAHA.108.119990.

Grassi G., Arenare, F., Pieruzzi, F., Brambilla, G., Mancia, G. Sympathetic activation in cardiovascular and renal disease. J. Nephrol. 2009;22:190-195.
Guimaraes S., Mota A., Begonha R. The effectiveness of b-adrenoceptor stimulation and the contribution of $b$-adrenoceptors increase from the proximal to the distal part of the canine saphenous vein. Naunyn Schmiedebergs Arch. Pharmacol. 1993;347:596-600. DOI 10.1007/ BF00166942.

Guimaraes S., Moura D. Vascular adrenoceptors: an update. Pharmacol. Rev. 2001;53(2):319-356.

Hein L., Altman J.D., Kobilka B.K. Two functionally distinct alpha2-adrenergic receptors regulate sympathetic neurotransmission. Nature. 1999:402:181-184. DOI 10.1038/46040.

Hering D., Lachowska K., Schlaich M. Role of the Sympathetic Nervous System in Stress-Mediated Cardiovascular Disease. Curr. Hypertens. Rep. 2015;17(10):80. DOI 10.1007/s11906-015-0594-5.

Jähnichen S., Eltze M., Pertz H. Evidence that alpha (1B)-adrenoceptors are involved in noradrenaline-induced contractions of rat tail artery. Eur. J. Pharmacol. 2004;488(1-3):157-67. DOI 10.1016/j. ejphar.2004.02.020.

Luo M., Hess M.C., Fink G.D., Olson L.K., Rogers J., Kreulen D.L., Dai X., Galligan J.J. Differential alterations in sympathetic neurotransmission in mesenteric arteries and veins in DOCA-salt hypertensive rats. Auton Neurosci. 2003;104(1):47-57. DOI 10.1016/S1566-0702(02)00287-4.

Markel A.L. Development of a new strain of rats with inherited stressinduced arterial hypertension. Genetic Hypertension. Ed. J. Sassard. London: John Libbey Eurotext. 1992;218:405-407.

Markel A.L., Maslova L.N., Shishkina G.T., Bulygina V.V., Machanova N.A., Jacobson G.S. Development influences on blood pressure regulation in ISAH rats, Development of the Hypertensive Phenotype: Basic and Clinical Studies. Handbook Hypertension. Elsevier, Amsterdam. 1999;19:495-526.

Markel A.L., Redina O.E., Gilinsky M.A., Dymshits G.M., Kalashnikova E.V., Khvorostova Yu.V., Fedoseeva L.A., Jacobson G.S. Neuroendocrine profiling in inherited stress-induced arterial hypertension rat strain with stress-sensitive arterial hypertension. J. Endocrinol. 2007;195:439-450. DOI 10.1677/JOE-07-0254.

Michel M.C., Brodde O.E., Insel P.A. Peripheral Adrenergic Receptors in Hypertension. Hypertension. 1990;16:107-120.

Morel Y., Schiano de Colella J.M., Harrop J., Deen K.C., Holmes S.D., Wattam T.A., Khandekar S.S., Truneh A., Sweet R.W., Gastaut J.A., Olive D., Costello R.T. Reciprocal expression of the TNF family receptor herpes virus entry mediator and its ligand Light on activated T cells: Light down-regulates its own receptor. J. Immunol. 2000;165:4397-4404. DOI 10.4049/jimmunol.165.8.4397.

O'Donnell S.R., Wanstall J.C. Beta-1 and beta-2 adrenoceptor-mediated responses in preparations of pulmonary artery and aorta from young and aged rats. J. Pharmacol. Exp. Ther. 1984;228:733-738.

Piascik M.T., Kusiak J.W., Barron K.W. a1-Adrenoceptor subtypes and the regulation of peripheral hemodynamics in the conscious rat. Eur. J. Pharmacol. 1990;186(2-3):273-278. DOI 10.1016/00142999(90)90443-a

Ranheim E.A., Cantwell M.J., Kipps T.J. Expression of CD27 and its ligand, CD70, on chronic lymphocytic leukemia B cells. Blood. 1995;85(12):3556-3565.

Red-Horse K., Drake P.M., Gunn M.D., Fisher S.J. Chemokine ligand and receptor expression in the pregnant uterus. Reciprocal patterns in complementary cell subsets suggest functional roles. Am. J. Pathol. 2001;159(6):2199-2213. DOI 10.1016/S0002-9440(10)63071-4.

Shen Y.T., Zhang H., Vatner S.F. Peripheral vascular effects of beta-3 adrenergic receptor stimulation in conscious dogs. J. Pharmacol. Exp. Ther. 1994;268:466-473.

Wilkinson H.A., Fitzgerald K., Greenwald I. Reciprocal changes in expression of the receptor lin-12 and its ligand lag-2 prior to commitment in a C. elegans cell fate decision. Cell. 1994;79(7):1187-1198. DOI 10.1016/0092-8674(94)90010-8. 